\title{
Er:YAG laser-assisted filtration surgery: initial results in rabbits
}

\author{
Noa Kapelushnik, Ari Leshno*, Reut Singer, Ruth Huna-Baron, Yaniv Barkana and Alon Skaat
}

\begin{abstract}
Background: Glaucoma is a leading cause of global blindness, especially preventable blindness. The increased prevalence of glaucoma has led to a growing demand for newer, safer, more rapid, and simpler treatments for the reduction of intraocular pressure (IOP). In this study, we evaluated the safety and feasibility of performing filtration glaucoma surgery with an Ab-Interno Er:YAG laser in rabbits.

Methods: Nine New Zealand White rabbits age 16 weeks were studied. After subconjunctival injection of mitomycin $C(M M C)$, a novel Ab-Interno Er:YAG laser probe was inserted into the anterior chamber $(A C)$ through a clear corneal $1 \mathrm{~mm}$ paracentesis and directed at the trabecular meshwork adjacent to the MMC injection area. A pulsed laser beam was applied to create a patent sclerostomy connecting the AC to the subconjuctival space, resulting in a filtering bleb. The laser system used was the Er:YAG laser system - LAS25-FCU, (Pantec Biosolutions AG, Liechtenstein). Parameters used: Wave lengh: 2940 nm, Pulse length: 100-400 $\mu$ sec,frequency: $250 \mathrm{~Hz}$. Average laser power in accordance to the fiber tip diameter: $0.85 \mathrm{~W}$ (range $0.8-0.92 \mathrm{~W}$ ). Complete ocular exams, including IOP measurements, were performed on $1,7,14$, and 23 days postoperatively. Three rabbits were sacrificed on days 1,14 , and 23, and histological examinations were performed on all nine eyes.

Results: All procedures resulted in a functional medium-large superior bleb without significant complications. The bleb was sustained in all rabbits by day 14 and in one of the three rabbits that reached the last follow-up at 23 days. No cases of postoperative hypotony were observed. There was a transient significant reduction in mean IOP on postoperative days 5 and $7(P=0.028)$. Histopathological analysis revealed a patent full-thickness scleral tunnel with only a minor degree of surrounding coagulation necrosis.
\end{abstract}

Conclusions: The Ab-Interno laser sclerostomy procedure is potentially safe and effective based on initial experience in an in-vivo rabbit animal model.

Keywords: Ab interno, Glaucoma, Minimal invasive, Trabeculectomy

\section{Background}

Glaucoma is a leading cause of global blindness, especially preventable blindness [1], with an estimate of nearly 76 million patients in 2020 and 111.8 million in 2040 [2]. Elevated intraocular pressure (IOP) is the single-most important risk factor for the development and progression of the disease [3]. The rise in IOP

\footnotetext{
*Correspondence: arileshno@gmail.com

Sam Rothberg Glaucoma Center, Goldschleger Eye Institute, Sheba Medical Center, Tel-Hashomer, Israel, affiliated to the Sackler Faculty of Medicine, Tel-Aviv University, Tel Aviv, Israel
}

results from decreased flow through the primary drainage root due to obstruction of the trabecular meshwork (TM). The only currently available treatment modality is lowering IOP to a safe level which slows or halts further optic nerve damage and consequent visual field loss [4, 5]. Surgical lowering of IOP is still most commonly performed by trabeculectomy [6] following its introduction by Cairns in 1968 [7]. Reduction of IOP is achieved by creating an alternative pathway for drainage of the aqueous humor through the sclera to form a filtering bleb underneath the conjunctiva. Despite the development of

(c) The Author(s). 2021 Open Access This article is licensed under a Creative Commons Attribution 4.0 International License, which permits use, sharing, adaptation, distribution and reproduction in any medium or format, as long as you give appropriate credit to the original author(s) and the source, provide a link to the Creative Commons licence, and indicate if changes were made. The images or other third party material in this article are included in the article's Creative Commons licence, unless indicated otherwise in a credit line to the material. If material is not included in the article's Creative Commons licence and your intended use is not permitted by statutory regulation or exceeds the permitted use, you will need to obtain permission directly from the copyright holder. To view a copy of this licence, visit http://creativecommons.org/licenses/by/4.0/. The Creative Commons Public Domain Dedication waiver (http://creativecommons.org/publicdomain/zero/1.0/) applies to the data made available in this article, unless otherwise stated in a credit line to the data. 
newer surgical methods, the main principle remains lowering the IOP by bypassing the obstructed TM. There is a growing demand for newer, safer, more rapid, and simpler treatments for IOP reduction in light of the everincreasing prevalence of glaucoma [2].

In this study, we report our experience with a novel delivery system of Er:YAG laser for ab-interno trabeculectomy in an animal model.

\section{Material and methods}

\section{Animals}

Approval for this study was obtained by the Israel national ethics committee for experiments in animals bioethics committee permission number- IL-18-10-261.

We tested the safety and efficacy of the new procedure in New Zealand White male rabbits aged 16 weeks. In each rabbit one eye was randomly selected. Prior to the surgical procedure, both eyes of each test animal underwent complete ocular examination for the detection of any abnormalities. Baseline IOP was measured with a tonometer (Tono-pen ${ }^{\circ} \mathrm{XL}$ ), and color photos of both the anterior and posterior segments were taken.

\section{Laser system}

The ab-interno procedure was performed with a thermal-ablating laser system- LAS25-FCU (Pantec Biosolutions AG, Liechtenstein). The system contains a miniaturized original equipment manufacturer laser diode driver (LDD) driving a 3 mikron $^{\text {ma }}$ laser (Er:YAG) operates at a $2940 \mathrm{~nm}$ wavelength with a pulse duration of $100-400 \mu \mathrm{sec}$, a frequency of $250 \mathrm{~Hz}$, average output power of $0.85 \mathrm{~W}$ (range $0.8-0.92 \mathrm{~W}$ ), repetition rates of up to $2 \mathrm{kHz}$ and delivers train of pulses. Laser energy is delivered through an optical fiber, a handpiece, and a solid core fiber-tip with a diameter of $320 \mu \mathrm{m}$ (Fig. 1). The fiber tip is protected against mechanical stress, and isolated from any risk of thermal dispersion by a stainless-steel tube. Further details regarding the system are available online (Additional file 1).

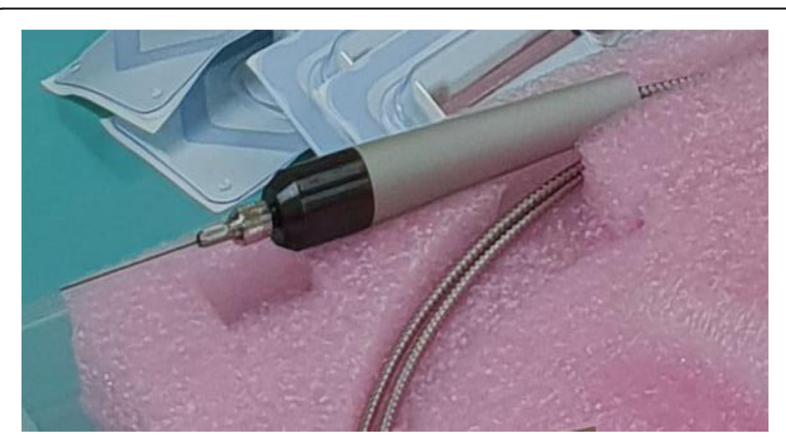

Fig. 1 Handpiece of the thermal ablating laser system

\section{Procedures}

All procedures were performed with the animals under general anesthesia by one of the authors (AS). Mitomycin $C(M M C)$ was injected to the superior subconjunctival space at the intended site for generating the drainage channel (Fig. 2a). After filling the anterior chamber (AC) with ophthalmic viscoelastic solution (Biolon ${ }^{\circ}$ ), the laser probe was inserted through an inferior $1 \mathrm{~mm}$ clearcorneal incision (Fig. 2b). Tissue ablation was induced by activating the laser with the optical fiber -tip placed juxtaposed to the target tissue, touching the trabecular meshwork, creating a new drainage channel from the $\mathrm{AC}$ to the subconjunctival space. Ablations were performed through a train of short pulses and high-peak power. The surgeon activated the laser ablating action and advanced the laser fiber until the fiber tip was visualized exiting the sclera into the subconjunctival space (Fig. 2c). The viscoelastic solution was re-injected into the AC to maintain AC depth at the end of the procedure. The tunnel site was marked by corneal tattooing, and Maxitrol and synthomycin 5\% ointments were applied to the experimental eye. A video of the procedure can be viewed online (Additional file 2).

\section{Follow-up and outcome measures}

A complete ocular examination was performed on postoperative days $1,7,14$, and 23 , and it included slit-lamp examination of the anterior and posterior segments and IOP measurements with a tonometer (Tono-pen ${ }^{\circ} \mathrm{XL}$ ). All examinations were done while the animals were awake. Location, size, and functionality of the conjunctival bleb were recorded for each animal, as well as anterior chamber depth, signs of inflammation or other possible side effects (Table 1).

Three animals, each time, were euthanized on postoperative days 1, 14, and 23 by an intravenous overdose of Na-pentobarbital. The experimental eye was enucleated and preserved in formalin $4 \%$ for histological evaluations which were performed with $H \& E$ stain. The diameter and length of the ablation tunnel were measured in each experimental eye, and the samples were also evaluated for signs of collateral thermal damage.

A $P$ value of $<0.05$ was considered statistically significant. Data were analyzed with SPSS software version 24.0 (SPSS Inc., Chicago, IL).

\section{Results}

\section{Procedure}

The procedure itself was uneventful, with immediate formation of a functional medium-large superior bleb in all cases. None of the experimental eyes showed signs of intraoperative corneal edema, hemorrhage, iridocorneal touch, or iris incarceration in the sclerotomy. Functional anterior blebs were observed in all cases on the first 


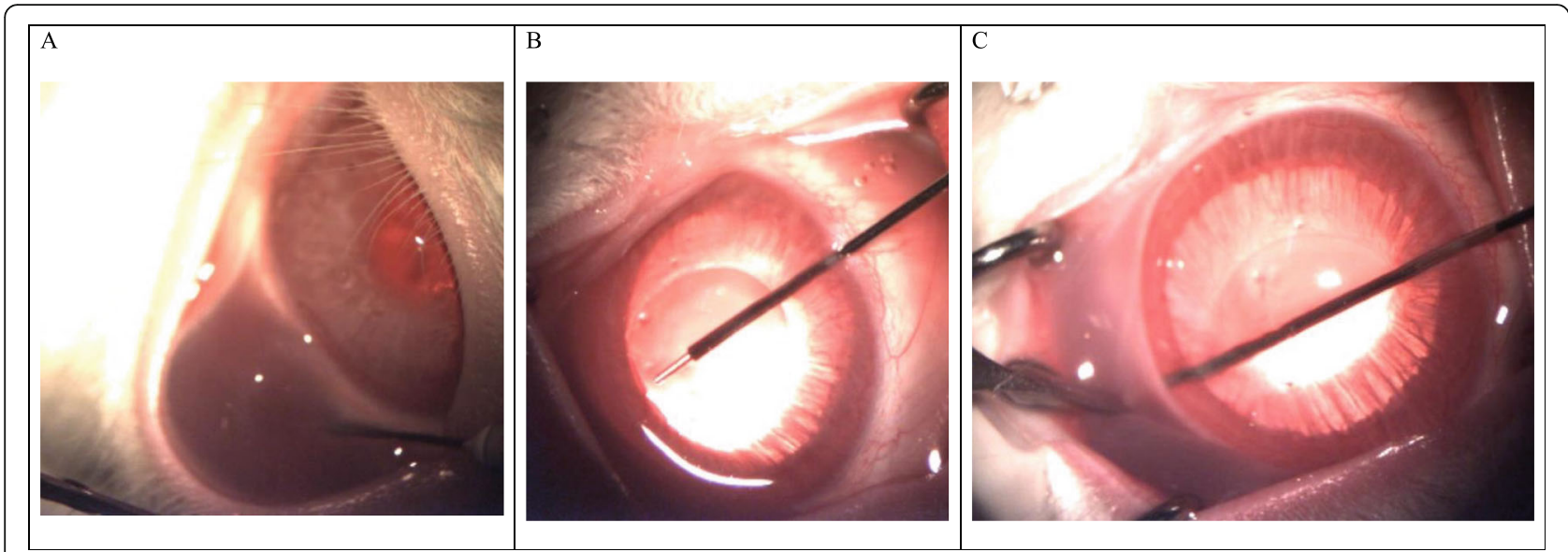

Fig. 2 Examples of procedure stages. a Injection of mitomycin C into the subconjunctival space; $\mathbf{b}$ insertion of the probe into the anterior chamber through a $1 \mathrm{~mm}$ clear corneal incision; c formation of the tunnel by using the ablative laser (the forceps tip points are at the end of the tip inside the formed bleb under the conjunctiva)

postoperative day ( $>3$ clock hours). All eight eyes had a quiet appearance with no sign of inflammation. The AC was intermediate-deep, similar to the preoperative status, with no signs of choroidal effusion. A linear lens opacity was noted in four eyes, most likely attributable to inadvertent device contact with the anterior capsule during the procedure. The pupil was found to be dilated and non-reactive in all eight eyes, however, no iridocorneal touch or iris incarcerations were observed. One eye exhibited microhyphema, which resolved by the 7-day follow-up evaluation. Bleb formation was maintained at day 14 in five out of the six (87\%) rabbits which were not sacrificed by that point. One of the three rabbits that reached the last follow-up examination on day $23 \mathrm{had}$ a functional bleb.

No cases of hypotony were observed during the follow-up. There was a transient significant reduction in mean IOP on postoperative days 5 and $7(12.9 \pm 2.3$ $\mathrm{mmHg}$ vs. $6.8 \pm 1.6 \mathrm{mmHg}$ and $8.2 \pm 0.9 \mathrm{mmHg}$, respectively, paired Wilcoxon signed rank test, $P=0.028$ ). However, the reduction diminished and became nonsignificant on postoperative days 14 and $23(10.6 \pm 3.6$ and $10.1 \pm 2.0$ respectively, $P>0.05$ ).

\section{Histopathological evaluation}

The mean ablated tunnel diameter was $133 \mu \mathrm{m}(n=1)$, $138.9 \pm 90 \mu \mathrm{m}(n=3)$, and $333.9 \pm 255 \mu \mathrm{m}(n=2)$ at the $1-, 14-$, and 23-day time points, respectively. The corresponding mean ablated tunnel lengths were $560 \mu \mathrm{m}$, $410.7 \pm 110.5 \mu \mathrm{m}$, and $401.2 \pm 210.4 \mu \mathrm{m}$. A minor degree of coagulation necrosis was noted lateral to the tunnel formation at all three time points, but a single case at the 14days' time-point,which no coagulation necrosis was detected. All examined samples (6) exhibited iris incarceration within the created tunnel (Fig. 3).

\section{Discussion}

The therapeutic application of lasers in ophthalmology and.specifically, in glaucoma is widespread and increasing. The different types of lasers allow for their utilization in a variety of conditions, such as iridotomy, trabeculoplasty, iridoplasty, and cyclophotocoagulation [8]. The rationale behind applying laser energy to create a filtering sclerostomy was that such concentrated energy can improve surgical accuracy and reduce any unnecessary tissue damage. The severity of thermal damage adjacent to the sclerostomy site is believed to be harmful to the long-term success and maintenance of fistula patency [9].The characteristics of the Erbium-doped Yttrium Aluminum Garnet laser (Er:YAG laser) make it a good candidate for the creation of long-standing intraocular openings. While the laser is capable of removing tissue by ablation [10], it is extensively absorbed by water, thus confining the energy to the desired area and tissue, with minimal thermal damage. As demonstrated in this study, the Ab-Interno Er:YAG laser system can be used safely and effectively to facilitate a connection between the $\mathrm{AC}$ and the subconjunctival space.

The use of Er:YAG laser for filter surgery has been explored in the past. Those attempts were met with limited success mainly due to the lack of an efficient and reliable delivery system $[11,12,10]$. There have also been several attempts to use Er:YAG laser emission in filtration surgery $[11,10,13,14]$. The main obstacle for the application of that laser type is the lack of a reliable delivery system due to the extensive absorption in water [13].

Hill et al. [10] described their experience with Er:YAG lasers in both iridotomy and sclerostomy in pigmented rabbit eyes (Dutch Cross rabbits). Those authors used two types of laser fiber-optic probes of $600 \mu \mathrm{m}$ and $400 \mu \mathrm{m}$ diameters. The sclerostomies were occluded on 
Table 1 Intra ocular pressure, anterior chamber depth and bleb sizes, pre and post operatively

\begin{tabular}{|c|c|c|c|c|c|c|}
\hline Rabbit \# & & Pre-Op & 1-day POD & 1-week POD & 2-weeks POD & 3-weeks POD \\
\hline \multirow{3}{*}{$\# 507$} & $\begin{array}{c}\mathrm{IOP} \\
(\mathrm{mmHg})\end{array}$ & 17 & 11 & & & \\
\hline & $\begin{array}{l}\text { Bleb size } \\
\text { (clock } \\
\text { hours) }\end{array}$ & & 7 (through 12) to 5 & & & \\
\hline & AC depth & Intermediate & Intermediate & & & \\
\hline \multirow{3}{*}{$\# 546$} & $\begin{array}{c}\mathrm{IOP} \\
(\mathrm{mmHg})\end{array}$ & 13 & 6 & & & \\
\hline & $\begin{array}{l}\text { Bleb size } \\
\text { (clock } \\
\text { hours) }\end{array}$ & & & & & \\
\hline & $A C$ depth & Shallow & Deep & & & \\
\hline \multirow{3}{*}{$\# 419$} & $\begin{array}{c}\mathrm{IOP} \\
(\mathrm{mmHg})\end{array}$ & 11 & 11 & & & \\
\hline & $\begin{array}{l}\text { Bleb size } \\
\text { (clock } \\
\text { hours) }\end{array}$ & & 7 (through 12) to 3 & & & \\
\hline & AC depth & Shallow & Intermediate & & & \\
\hline \multirow{3}{*}{$\# 418$} & $\begin{array}{c}\mathrm{IOP} \\
(\mathrm{mmHg})\end{array}$ & 14 & 11 & 9 & 9 & \\
\hline & $\begin{array}{l}\text { Bleb size } \\
\text { (clock } \\
\text { hours) }\end{array}$ & & 7 (throu & 10 (through 12) to 2 & & \\
\hline & AC depth & Shallow & Intermediate & Intermediate & Intermediate & \\
\hline \multirow{3}{*}{$\# 474$} & $\begin{array}{c}\mathrm{IOP} \\
(\mathrm{mmHg})\end{array}$ & 10 & 11 & 7 & 7 & \\
\hline & $\begin{array}{l}\text { Bleb size } \\
\text { (clock } \\
\text { hours) }\end{array}$ & & 9 (through 12) to 3 & 11 (through 12) to & 11 (through 12) to 3 & \\
\hline & AC depth & Intermediate & Intermediate & Intermediate & Intermediate & \\
\hline \multirow{3}{*}{$\# 477$} & $\begin{array}{c}\mathrm{IOP} \\
(\mathrm{mmHg})\end{array}$ & 14 & 25 & 9 & 16 & \\
\hline & $\begin{array}{l}\text { Bleb size } \\
\text { (clock } \\
\text { hours) }\end{array}$ & & 7 (through 12) to 3 & Flat & flat & \\
\hline & AC depth & Shallow & Intermediate & Intermediate & Intermediate & \\
\hline \multirow{3}{*}{$\# 476$} & $\begin{array}{c}\mathrm{IOP} \\
(\mathrm{mmHg})\end{array}$ & 10 & 12 & 7 & 14 & 12 \\
\hline & $\begin{array}{l}\text { Bleb size } \\
\text { (clock } \\
\text { hours) }\end{array}$ & & 7 (through 12) to 3 & $\begin{array}{c}10 \text { (through 12) to } \\
2\end{array}$ & 9 (through 12) to 1 & flat \\
\hline & AC depth & Shallow & Deep & Intermediate & Deep & Deep \\
\hline \multirow{3}{*}{$\# 438$} & $\begin{array}{c}\mathrm{IOP} \\
(\mathrm{mmHg})\end{array}$ & 14 & 9 & 8 & 8 & 8 \\
\hline & $\begin{array}{l}\text { Bleb size } \\
\text { (clock } \\
\text { hours) }\end{array}$ & & 7 (through 12) to 5 & 8 (through 12) to 2 & 9 (through 12) to 2 & 7 (through 12) to 2 \\
\hline & AC depth & Shallow & Intermediate & Intermediate & Intermediate & Intermediate \\
\hline \multirow{3}{*}{$\# 391$} & $\begin{array}{c}\text { IOP } \\
(\mathrm{mmHg})\end{array}$ & 13 & 12 & 9 & 10 & 10 \\
\hline & $\begin{array}{l}\text { Bleb size } \\
\text { (clock } \\
\text { hours) }\end{array}$ & & 7 (through 12) to 2 & 9 (through 12) to 3 & 10 (through 12) to 1 & flat \\
\hline & AC depth & Shallow & Intermediate & Intermediate & Intermediate & Intermediate \\
\hline
\end{tabular}




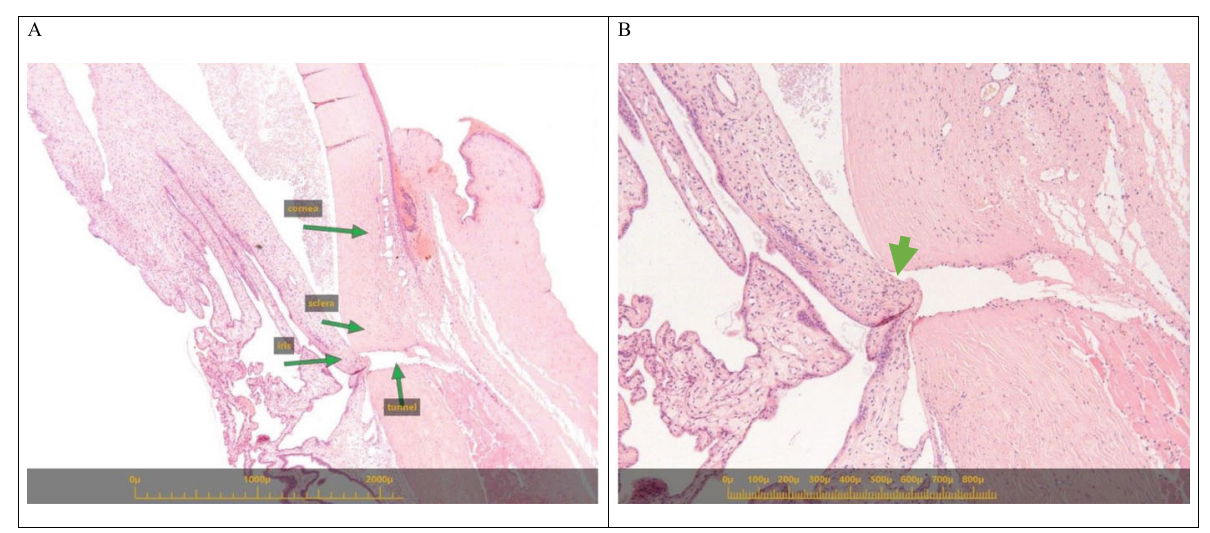

Fig. 3 Eye 419R (One day post operation) - Photomicrograph of the "treated" (ablated) side (a) with anatomical indications; b higher magnification demonstrating the induced tunnel and iris incarceration (arrow)

postoperative day 1 in eight of their 10 rabbits operated by means of the $600 \mu \mathrm{m}$ probe and eventually exhibited inflammation, fibrin production, and peripheral corneal decomposition. Their experience with the thinner $400 \mu \mathrm{m}$ fiber optic probe was more successful. The sclerostomies remained patent until all eight animals were sacrificed in the first postoperative week, and none experienced serious complications. Using an Er:YAG laser, McHam et al. introduced a single crystal sapphire fiber optic which was found effective for delivering the laser with minimal thermal damage due to an attenuation rate compatible with the procedure and producing an effective method for an ab externo sclerotomy. Mizota et al. investigated the optimal pulse energy for sclerostomy in enucleated bovine eyes, and concluded that the optimal energy for full thickness sclerostomy with minimal thermal damage is $2 \mathrm{~mJ}$ [15].

The procedure we followed in our study has several advantages over previously described methods. First, our delivery system used a $320 \mu \mathrm{m}$ GeO2 optical fiber with a biocompatible $250 \mu \mathrm{m}$ sapphire fiber tip. The small caliber enables insertion of the probe through a small (1 $\mathrm{mm}$ ) clear corneal incision such as that used in most anterior segment surgeries. In this way, this novel delivery system transformed the traditional trabeculectomy into a sutureless procedure. Furthermore, the surgical approach became more familiar to the surgeon with greater maneuverable capability and with a very short learning curve. Thanks to these advantages, the surgeon was able to position the probe at the correct position, juxtaposed to the TM, with a relative high level of accuracy, as evidenced by the adjacent thermal damage of only $55 \mu \mathrm{m}$, similar to the $50 \mu \mathrm{m}$ achieved by Mizota et al. only with the assistance of an endoscopic system for direct visualization [14].

We used MMC to reduce the possibility of occlusion of the scleral tunnel created by the Er:YAG laser.
Although our sample size was small, these preliminary results indicate that the procedure is effective in creating a sustainable functional bleb (Fig. 4). It should also be noted that none of the experimental eyes developed postoperative hypotony, thanks to the accurately sized scleral ablation tunnel. While we did observe a reduction in IOP, given the normal low baseline IOP, our sample size was too small to show statistical significance past the first post-operative week. Despite the use of a smaller gauge probe, we observed a high rate of iris incarceration in the histopathologic evaluation. However, since no signs of iris incarceration were observed during the in-life ophthalmological evaluation, it cannot be determined at this point whether the iris incarceration occurred during the in-life phase or post mortem during the processing phase. Regardless of the timing, it should be taken into account that the incarceration may have affected the tunnel diameter dimensions.

This study has several limitations important mentioning. Rabbits are frequently used in ophthalmology research, mainly due to the favorable size of the eye and the anatomical resemblance to the human eye, however, this model presents some limitations for our device given that the rabbit eye normally has a very narrow angle and relatively shallow anterior chamber. In addition, the structure of the iridocorneal angle and wound healing characteristics is different of that of humans. This difference can affect the fistula formation and the procedure complications when applied on human eyes. Our research histology demonstrated that despite advancement of the probe tip through the fistula into the subconjunctival space during the surgery the fistula was sized less than the probe tip size This would suggest that significant tissue shrinkage has occurred. Furthermore the dimension of the fistula at the last time point is nearly twice the sizes observed early on, with a corresponding increase in variability indicating that it 


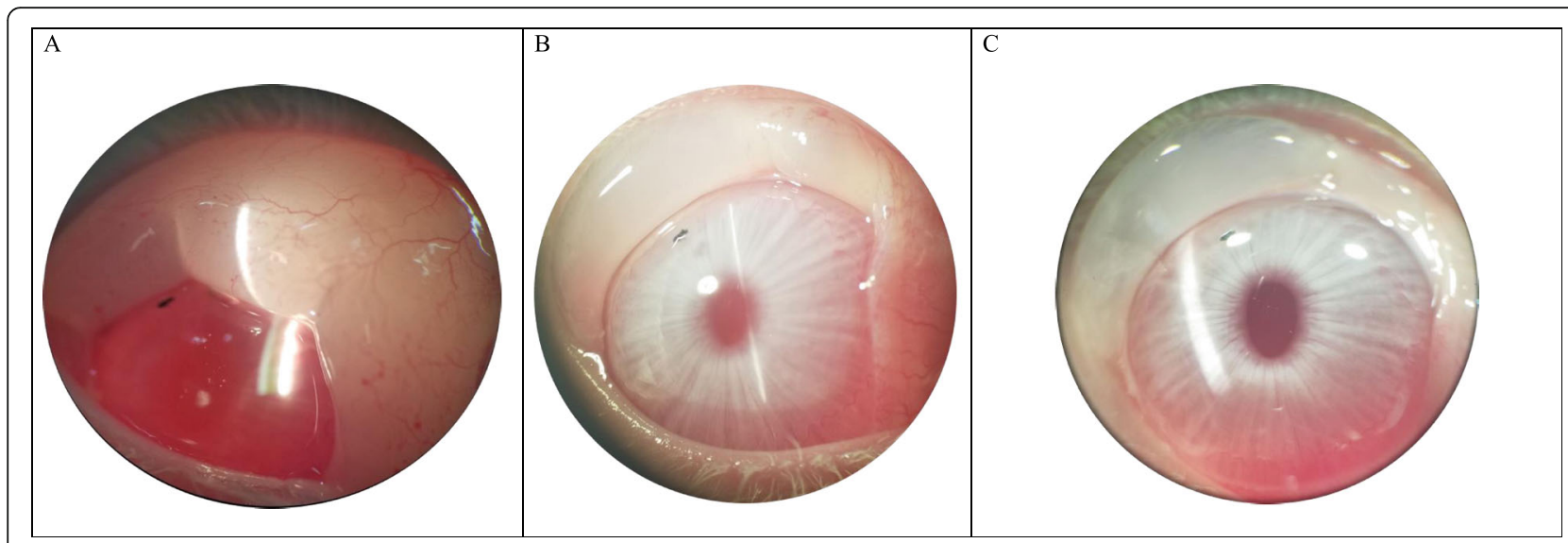

Fig. 4 Example images of the post-operative functional bleb at day 1 (a) 7 (b) and 14 (c) post-op

might be difficult to predict the fistula's size. Albeit the small sample size, the results regarding both the intraocular pressure, functioning bleb and procedure complications were quite homogeneous, with small divergence. These results need to be confirmed in a larger study which might also help detect possible indicators for the variability in fistula size as well as determine the procedures long-term efficacy.

\section{Conclusion}

The in-vivo application of the Ab-Interno Er:YAG laser procedure in a rabbit model is feasible and safe due to the relatively minor coagulation necrosis lateral to the tunnel formation. We confirmed that it was feasible to induce a tunnel within the sclera by means of the procedure. A current fiber diameter of $320 \mu \mathrm{m}$ induced the generation of a large bleb with IOP reduction for several days in the rabbit eye, with no hypotony or flat AC. These changes in the eyes are considered to be favorable according to the recently published position paper dealing with assessment of adversity in animal research, since the intentionally induced tunnel in the sclera was well circumscribed and not associated with damage to adjacent or distant ocular structures [16]. Further studies are required to confirm the best fiber diameter for achieving the maximum efficacy and highest safety profile that will not generate any risk to human eyes.

\section{Supplementary Information}

The online version contains supplementary material available at https://doi. org/10.1186/s12886-021-01986-4.

Additional file 1.

Additional file 2

Acknowledgements

Not applicable.
Authors' contributions

NK was a major contributor in writing the manuscript, revising the manuscript and Approval of the version of the manuscript to be published. AL was a major contributor in conception and design of study, writing the manuscript, revising the manuscript and Approval of the version of the manuscript to be published. RS was a major contributor in analyzing and interpretating of data, revising the manuscript and Approval of the version of the manuscript to be published. RHB was a major contributor in analyzing and interpretating of data, revising the manuscript and Approval of the version of the manuscript to be published. YB was a major contributor in analyzing and interpretating of data, revising the manuscript and Approval of the version of the manuscript to be published. AS was a major contributor in conception and design of study, writing the manuscript, revising the manuscript and Approval of the version of the manuscript to be published.

\section{Funding}

Study was financed by IOPtima Ltd., Caesarea, Israel. None of the authors have financial or other conflict of interest to declare.

Availability of data and materials

The datasets used and/or analysed during the current study are available from the corresponding author on reasonable request.

\section{Declarations}

Ethics approval and consent to participate

Approval for this study was obtained by the Israel national ethics committee for experiments in animals. It adhered to the ARVO Statement for the Use of Animals in Ophthalmic and Vision Research and was carried out in compliance with the ARRIVE guidelines.

Consent for publication

Not applicable.

\section{Competing interests}

The authors declare that they have no competing interests.

Received: 10 February 2021 Accepted: 6 May 2021

Published online: 20 May 2021

\section{References}

1. Quigley HA. The number of people with glaucoma worldwide in 2010 and 2020. Br J Ophthalmol. 1996;80(5):389-93. https://doi.org/10.1136/ bjo.80.5.389.

2. Tham Y-C, Li X, Wong TY, Quigley HA, Aung T, Cheng C-Y. Global prevalence of glaucoma and projections of glaucoma burden through 2040. Ophthalmology. 2014;121(11):2081-90. https://doi.org/10.1016/j. ophtha.2014.05.013. 
3. Blumberg D, Skaat A, Liebmann JM. Emerging risk factors for glaucoma onset and progression. Prog Brain Res. 2015;221:81-101. https://doi.org/10.1 016/bs.pbr.2015.04.007.

4. Gaasterland DE, Ederer F, Beck A, et al. The advanced Glaucoma intervention study (AGIS): 7. The relationship between control of intraocular pressure and visual field deterioration. Am J Ophthalmol. 2000;130(4):42940. https://doi.org/10.1016/S0002-9394(00)00538-9.

5. Heijl A, Leske MC, Bengtsson B, Hyman L, Bengtsson B, Hussein M. Reduction of intraocular pressure and glaucoma progression: results from the early manifest Glaucoma trial. Arch Ophthalmol. 2002;120(10):1268-79. https://doi.org/10.1001/archopht.120.10.1268.

6. Koike KJ, Chang PT. Trabeculectomy. Int Ophthalmol Clin. 2018;58(3):117-33. https://doi.org/10.1097/II0.0000000000000231.

7. Cairns JE. Trabeculectomy. Preliminary report of a new method. Am J Ophthalmol. 1968;66(4):673-9. https://doi.org/10.1016/0002-9394(68)91288-9.

8. Kumar H, Mansoori T, Warji G, Somarajan B, Bandil S, Gupta V. Lasers in glaucoma. Indian J Ophthalmol. 2018;66(11):1539-53. https://doi.org/10.41 03/ijo.IJO_555_18.

9. Geffen N, Ton Y, Muñoz G, Mariotti C, Assia El. CO2 laser-assisted sclerectomy surgery for open-angle glaucoma. Eur Ophthalmic Rev. 2012; 06(01):12. https://doi.org/10.17925/eor.2012.06.01.12.

10. Hill RA, Le MT, Yashiro H, et al. Ab-interno erbium (Er):YAG laser sclerostomy with iridotomy in Dutch cross rabbits. Lasers Surg Med. 1993;13(5):559-64. https://doi.org/10.1002/lsm.1900130511.

11. Jacobi PC, Dietlein TS, Krieglstein GK. Prospective study of Ab externo erbium: YAG laser sclerostomy in humans. Am J Ophthalmol. 1997;123(4): 478-86. https://doi.org/10.1016/50002-9394(14)70173-4.

12. Schuman JS, Stinson WG, Hutchinson BT, Bellows AR, Puliafito CA, Lytle R. Holmium laser sclerectomy: success and complications. Ophthalmology. 1993;100(7):1060-5. https://doi.org/10.1016/S0161-6420(93)31538-1.

13. McHam ML, Eisenberg DL, Schuman JS, Wang N. Erbium: YAG laser trabecular ablation with a sapphire optical fiber. Exp Eye Res. 1997;65(2): 151-5. https://doi.org/10.1006/exer.1996.0274.

14. Mizota A, Takasoh M, Kobayashi K, Parel JM, Manns F, Rol P. Internal sclerostomy with the Er:YAG laser using a gradient-index (GRIN) endoscope. Ophthalmic Surg Lasers. 2002;33(3):214-20. https://doi.org/10.3928/1542 8877-20020501-08

15. Mizota A, Takasoh M, Tsuyama Y, Kobayashi K, Momiuchi M. Sclerostomy with an erbium YAG laser -the relationship with pulse energy. I Japanese Ophthalmol Soc. 2000;104(7):453-7. https://doi.org/10.1016/s0021-51 55(00)00322-1.

16. Kerlin R, Bolon B, Burkhardt J, Francke S, Greaves P, Meador V, et al. Scientific and regulatory policy committee: recommended ("best") practices for determining, communicating, and using adverse effect data from nonclinical studies. Toxicol Pathol. 2016;44(2):147-62. https://doi.org/10.11 77/0192623315623265.

\section{Publisher's Note}

Springer Nature remains neutral with regard to jurisdictional claims in published maps and institutional affiliations.

Ready to submit your research? Choose BMC and benefit from:

- fast, convenient online submission

- thorough peer review by experienced researchers in your field

- rapid publication on acceptance

- support for research data, including large and complex data types

- gold Open Access which fosters wider collaboration and increased citations

- maximum visibility for your research: over $100 \mathrm{M}$ website views per year

At $\mathrm{BMC}$, research is always in progress.

Learn more biomedcentral.com/submissions 